\title{
Can Emotional Intelligence Predict Individual Values?
}

\author{
Ilkay Ulutas ${ }^{1}$ and Sevim Karaoglu ${ }^{2}$ \\ ${ }^{1}$ Gazi University, Turkey. \\ ${ }^{2}$ The University of Sheffield, UK.
}

\begin{abstract}
Emotional Intelligence (EI) refers to the mental abilities associated with processing and responding to emotions, including recognizing the expression of emotions in others, using emotions to enhance thinking, and regulating emotions to drive effective behaviors. Emotional intelligence works together with character/values education and moral development. It has skills such as self-confidence, sensitivity, self-awareness, self-control, empathy, optimism, and social skills which are also considered as personal values. The results revealed that emotional intelligence fosters teacher's individual and institutional skills. Teachers with Higher EI can better understand themselves that know what and how they want to achieve, the way of use their resources effectively, and provide suitable solution to the problem. This allow them to fulfil personal values and institutional values in the school. In this sense, we aimed to associations between emotional intelligence and personal values of early childhood teacher trainees. 412 undergraduate students attending early childhood department of universities took part in this study. Trait Emotional Intelligence Scale short form and Values Scale were used as research tools. Data were analyzed to interpret emotional intelligence on personal values. Finding indicated associations between emotional intelligence and personal values. It was suggested future researches focusing on early childhood teacher socialization of emotion, and discussing theoretical and practical benefits of such research.
\end{abstract}

Keywords: Emotional intelligence, teachers, values.

\section{Introduction}

Today's world calls the people being more emotional and more awareness of self-development not only personally but also vocationally. It is expected that the EI how impact on the candidate of teachers' vocational values and their perspective of dealing with the challenges in their careers. Feelings and values are essential to work efficiency in professional life. The role of emotional intelligence (EI) in teaching and education has been widely searched by recent studies. It was found that EI negatively correlated with teacher born out, job satisfaction, exhaustion, stress and depression levels. Positively, teaching satisfaction, coping strategies, cultural intelligence of organization, self-efficiency, well-being, labour strategies [1], [2], [3], [4], [5], [6], [7].

Emotional intelligence provide the teachers priceless knowledge about self-concept, other people and diverse opportunities that people share their organizational environment [8]. There are some values that builds people's decisions, believes and defending their own ideas. The values are determinative for people's understanding their social and personal environment such as job issues, social networking [9]. Emotional intelligence helps to develop and understand the values in organizations. It is important that the values of educational settings lead to support students' social emotional development, social skills and to increase their academic success too. Also, the values are significant for teachers' communication and networking to develop their own self-development as well. Vocational values are helpful for making decision, motivation, communication and selection of management success [10]. In this regard, as Matthew and colleagues stated that "work and emotions are most plausibly construed to be reciprocally determined." [11]. From this perspective, it is clear that work environment and emotions are interwoven in each other's and hard to distinguish between them. This is due to the fact that both terms should be evaluated together in especially educational settings as discussed in this paper. EI would be 
taken into account as a core element of career as suggested by the researchers such as that Goleman (1995) highlighted that EI satisfactions such as social awareness, self and social management, social skills are important in vocational life and these all can be gained and these all are invaluable structure. [12]. Also the quantitative research, which conducted by Corcoran and Tormey in 2012 with 352 teacher candidates in an Irish University, showed that high level emotional competences provides advantages to teachers and students. According to the research, participants who had lower emotional skills are likely to have a decreased sense of their own feeling situation, sense of being control of their own feelings, they also reflected feeling bored, angry and negative impacts on their work [13]. The ability of teachers to manage their emotions, understanding of values and behaviors and to make meaningful friendships is an important prerequisite for work values and their vocational identities. As a result, the relevance of emotional intelligence and emotional labor we purposed to examine associations between emotional intelligence and personal values in the educational settings of teacher candidates. In accordance with the relevant literature our hypotheses that;

Hypotheses 1: There are associations between emotional intelligence and personal values in the educational settings.

Hypotheses 2: Emotional intelligence can predict personal values in the educational settings.

\section{Method}

\subsection{Participants}

Participants included 412 undergraduate students (388 girls, 24 boys) who attending early childhood department of universities in Ankara voluntarily took part in this study. Mean age was 21.06; 232 of them were fourth grade, 180 of them were first grade students.

\subsection{Measures}

\subsubsection{Trait Emotional Intelligence Questionnaire Short Form (TEIQue-SF)}

The TEIQue-SF consists of 30 items designed to measure global trait EI (e.g., I usually find it difficult to regulate my emotions; I'm usually able to influence the way other people feel). The TEIQue-SF is derived from the full form of the TEIQue, which covers 15 distinct facets grouped in four main factors (Well-being, emotionality, sociability, and self-control). Responses range from 1 (Strongly disagree) to 7 (Strongly agree) [14]. Turkish adaptation study of the TEIQue shown that Turkish TEIQue has 16 items under four factors and has .81 initial reliability [15].

\subsubsection{Values Scale}

This instrument evaluates perceived personal and organizational values in educational settings. The scale totally includes 50 items ranging from 1 (never) to 5 (totally). Each item evaluated from personal perception and organizational perception. Studying with undergraduates we had to use only personal perception. We modified content and the instructions of the scale to early childhood undergraduates. The internal consistency of the scale was $0.97(n=150)$. In addition Sperman-Brown two half test correlation was 0.91 for the individual part of the scale Alpha was, 0.95, fort the organizational part 0.96 [16].

\subsection{Procedure}

Data were collected in a 15-20 min sessions regular lecture periods of the universities, after receiving the approval of the institutions and instructors. Students voluntarily participated the research and were informed about aim of the research before the answering the measures. The trait EI questionnaire was applied first, followed by the values list and values ordering list. 


\section{Results}

First of all, bivariate correlation analysis was performed to test the association between emotional intelligence and personal values in the educational settings. As expected, results revealed a significant positive relationship among TEIQue factors, global TEIQue and personal values scores, $r=.19-36, \mathrm{p}=.01$ (Table 1).

TABLE I. Bivariate Correlations among TEIQue Factors, Global TEIQue and Personal Values

\begin{tabular}{|c|c|c|c|c|c|c|c|}
\hline & Means & SD & Wellbeing & Self-Control & Emotionality & Sociability & $\begin{array}{l}\text { Global } \\
\text { TEIQue }\end{array}$ \\
\hline Personal & \multirow{2}{*}{4.2589} & \multirow{2}{*}{.54063} & $.327^{* *}$ & $.194^{* *}$ & $.279^{* *}$ & $.299^{* *}$ & $.366^{* *}$ \\
\hline Values & & & .000 & .000 & .000 & .000 & .000 \\
\hline \multirow{2}{*}{ Wellbeing } & \multirow{2}{*}{5.1711} & \multirow{2}{*}{1.02486} & & $.320^{* *}$ & $.289^{* *}$ & $.461^{* *}$ & $.679^{* *}$ \\
\hline & & & & .000 & .000 & .000 & .000 \\
\hline \multirow{2}{*}{ Self-Control } & \multirow{2}{*}{4.4053} & \multirow{2}{*}{1.08328} & & & $.544^{* *}$ & $.427^{* *}$ & $.771^{* *}$ \\
\hline & & & & & .000 & .000 & .000 \\
\hline \multirow{2}{*}{ Emotionality } & \multirow{2}{*}{4.8004} & \multirow{2}{*}{1.15393} & & & & $.426^{* *}$ & $.772^{* *}$ \\
\hline & & & & & & .000 & .000 \\
\hline Sociability & 4.8289 & 1.03813 & & & & & $\begin{array}{r}.766^{* *} \\
.000\end{array}$ \\
\hline
\end{tabular}

**. Correlation is significant at the 0.01 level (2-tailed).

Secondly, with the purpose of examining the predictive validity of the TEIQue for the personal values, multiple regression analyses were conducted. Mean scores on the personal values were entered as dependent variables and wellbeing, emotionality, sociability, self-control and global TEIQue, entered as the independent variable. The effect of group was highly significant, $\mathrm{F}(416)=18.779, \mathrm{p}<.001$, and explained over $40 \%$ of the variance and the effect size can therefore be considered to be moderate.

Global TEIQue $(\beta=-.48, \mathrm{p}<.001)$ and self-control $(\beta=-.19, \mathrm{p}<.05)$ were significant predictor of personal values in the educational institution. However, wellbeing, with $\mathrm{t}=.96, \mathrm{p}=.335$ and sociability with $\mathrm{t}=-25$ $\mathrm{p}=.798$ were excluded because they did not contribute in significance to the variance of values for change.

Overall, these findings yield strong support for the hypothesis that individuals with higher levels of TEIQue would exhibit higher performance on personal values in the educational institutions.

TABLE II. Model Summary of Regression Analysis for Personal Values

\begin{tabular}{lccccc}
\hline \hline & $\mathrm{B}$ & Std. Error & $\beta$ & $\mathrm{t}$ & Sig. \\
\hline (Constant) & 2.986 & .153 & & 19.526 & .000 \\
Wellbeing & .038 & .039 & .071 & .966 & .335 \\
Self-control & -.095 & .046 & -.191 & -2.067 &. $\mathbf{0 3 9}$ \\
Sociability & -.011 & .043 & -.021 & -.256 & .798 \\
Global TEIQue & .323 & .105 & .481 & 3.068 & $\mathbf{. 0 0 2}$ \\
\hline \hline
\end{tabular}

a. Predictors: (Constant), b. Predictors: (Constant), wellbeing, self-control, sociability Total TEIQue

$\begin{array}{llll}\text { c. Dependent Variable: Personal Values } \quad R=.40 & R 2=.16 & F(416)=18.779 & p<.000\end{array}$

\section{Discussion}

The present study investigates effects of emotional intelligence on the personal values in the educational institutions. As expected, we found a positive correlation between trait EI and personal values. In addition, main 
finding of this study is that Global TEIQue and self-control are shown to be significant predictors of personal values in the educational settings. This result is in accordance with other studies' results which show that the teachers' emotional intelligence is a significant issue for the achieving organizational values and improving quality of education [17]. Values are socio-emotional characteristics of person. In regard to Hassan, Ishak and Bokhari (2011) found that there are four domains that significantly influence work values among educators: selfmotivation, empathy, social skills and spirituality [18]. Ateş \& Buluç (2015) also showed that there is a relationship between emotional intelligence of teachers and work commitment, providing and increasing emotional intelligence and motivation through education would bring an advantage in increasing organizational commitment [19]. Nordin (2011) revealed that emotional intelligence had contributed the strongest unique contribution to explain organizational readiness for change [20]. Colomesichi and Colomeischi (2014) stated the more emotional intelligent teachers are the more satisfied with their teaching job they are and also they have a more positive attitude towards work [21].

The results of this study highlight the effect of the emotional intelligence to predict personal values of the teacher candidates. Emotional intelligence is productive and improving factor for person and organization. Both to prevent from exhaustion, born out, depression and to fulfill the organizational values the programs and strategies are needed to help students to master these life skills [22], [23]. Corcoran \& Tormay (2012) stated candidate of teachers may need help in personal skills and also suggest that teacher education programs might need to place a particular emphasis on the skills of perceiving emotions in self and others, and of understanding emotional changes and progressions [13]. Via this particular programs EI skills of the teacher candidates can be strengthened as much as possible before the graduation.

This study has some limitations. First, we worked with first and fourth year students, next studies should be included all years. Second, we focus on the students' perceptions of personal values in the educational setting. Teacher candidates have limited vocational experiences in the educational setting. Thatis why they can be followed in future research to determine the experience effect on the personal values and emotional intelligence.

\section{Acknowledgments}

The authors wish to gratefully acknowledge the students who participated, and lecturers, early childhood departments for their support of this study.

\section{References}

[1] M Platsidou, "Trait emotional intelligence of Greek special education teachers in relation to burnout and job satisfaction”, School Psychology International, 31, 60-76, 2010. http://dx.doi.org/10.1177/0143034309360436

[2] D. W. Chan, "Emotional intelligence and components of burnout among Chinese secondary school teachers in Hong Kong", Teaching and Teacher Education, 22, 1042-1054, 2006. http://dx.doi.org/10.1016/j.tate.2006.04.005

[3] D. W . Chan, "Emotional intelligence, self-efficacy, and coping among Chinese prospective and in-service teachers in Hong Kong", Educational Psychology, 28, 397-408, 2008. http://dx.doi.org/10.1080/01443410701668372

[4] M. Karakuş, "Emotional intelligence and negative feelings: A gender specific moderated mediation model", Educational Studies, 39, 68-82, 2013. http://dx.doi.org/10.1080/03055698.2012.671514

[5] J. Karim, and R. Weisz, "Emotions at work: the role of emotional intelligence and emotional labor in predicting work-family conflict, psychological distress, and life satisfaction", International Journal of Arts \& Sciences, 2011.

[6] G. Näring, P. Vlerick, and B. Van de Ven, "Emotion work and emotional exhaustion in teachers: The job and individual perspective”, Educational Studies, 38, 63-72, 2012. 
http://dx.doi.org/10.1080/03055698.2011.567026

[7] A.Penrose, C. Perry, and I. Ball, "Emotional intelligence and teacher self efficacy: The contribution of teacher status and length of experience", Issues In Educational Research, 17, 2007.

[8] R. S. Lazarus, and C. A. Smith, "Emotion and adaptation". In Handbook of Personality: Theory and Research (Ed. L.A. Pervin), pp. 609-637, New York: Oxford University Press, 1990.

[9] E. Ozmete, “íş Yaşamında Değerler”. İstanbul: Kedim Yayıncılık, 2008.

[10] B. Z. Posner and J. M. Munson, "The importance of values in understanding organizational behavior", Human Resource Management, 18, 3, . 9-14, 1979.

[11] Matthews, G., Zeidner, M., and Roberts R. D. ( 2002). Emotional Intelligence: Science and Myth. New Baskerville: MIT Press.

[12] D. Goleman, “Emotional intelligence: why it can matter more than IQ”. New York: Bantam Books, 1995.

[13] R.P. Corcoran and R. Tormey, "How emotionally intelligent are pre-service teachers?", Teaching and Teacher Education, 28, 750-759, 2012.

http://dx.doi.org/10.1016/j.tate.2012.02.007

[14] K.V. Petrides, "Psychometric properties of the trait emotional intelligence questionnaire", In C. Stough, D. H. Saklofske, \& J. D. Parker (Eds.), Advances in the assessment of emotional intelligence, New York, NY: Springer, 2009. http://dx.doi.org/10.1007/978-0-387-88370-0_5

[15] M. E. Deniz, E. Ozer, and E. Isik "Trait Emotional Intelligence Questionnaire-Short Form: validity and reliability studies”, Education and Science, 38, 169, 2013.

[16] F. Sezgin, (2006) "Individual and organizational value congruence of elementary school teachers (Ankara sample)", Avaliable: https://tez.yok.gov.tr/UlusalTezMerkezi/tezSorguSonucYeni.jsp

[17] C. Birol, H. Atamturk, F. Silman, S. Sensoy, "Analysis of the emotional intelligence level of teachers", Procedia. Social and Behavioral Sciences, 1, 2606 - 2614, 2009.

http://dx.doi.org/10.1016/j.sbspro.2009.01.460

[18] S.N.S. Hassan,N.M. Ishak, and M. Bokhari, "Impacts of emotional intelligence (EQ) on work values of high school teachers", Procedia - Social and Behavioral Sciences, 30, 1688 - 1692, 2011.

http://dx.doi.org/10.1016/j.sbspro.2011.10.326

[19] O. T. Ates, \& B. Buluc, "The Relationship between the emotional intelligence, motivation and organizational commitment of primary school teachers", Middle Eastern \& African Journal of Educational Research, 17, 31-48, 2015.

[20] N. Nordin, “ The Influence of Emotional intelligence, Leadership Behaviour and Organizational Commitment on Organizational Readiness for Change in Higher Learning Institution", Procedia - Social and Behavioral Sciences, 29, $129-138,2011$. http://dx.doi.org/10.1016/j.sbspro.2011.11.217

[21] A.A. Colomeischi and T. Colomeischi, "Teachers' Attitudes towards Work in Relation with Emotional Intelligence and Self-Efficacy”, Procedia-Social and Behavioral Sciences, 159, 615 - 619, 2014.

http://dx.doi.org/10.1016/j.sbspro.2014.12.435

[22] F. C. Chen, F. C.Ku, Y. H. Shyr, F. H. Chen, and S. S. Chou, "Job demand, emotional awareness, and job satisfaction in internships: The moderating effect of social support", Social Behavior and Personality, 37, 14291440, 2009. http://dx.doi.org/10.2224/sbp.2009.37.10.1429

[23] M. Mikolajczak, C. Menil, and O. Luminet, "Explaining the protective effect of trait emotional intelligence regarding occupational stress: Exploration of emotional labor processes", Journal of Research in Personality, 41, 1107-1117, 2007.

http://dx.doi.org/10.1016/j.jrp.2007.01.003 